\title{
Online Modeling for Future Fashion Factory Based on 3D Multispectral Colour Imaging and Data Fusion
}

\author{
Sui-Xian $\mathrm{Li}^{1,2 *}$ \\ ${ }^{1}$ Laboratory of Color Imaging, Graphics and Appearance Management, Binzhou University, 256600,China \\ ${ }^{2}$ School of design, University of Leeds, UK
}

Submission: August 24, 2019; Published: September 11, 2019

*Corresponding author: Sui-Xian Li, Laboratory of Color Imaging, Graphics and Appearance Management, Binzhou University, 256600,China

\section{Mini Review}

An increasing demand for 3D appearance modeling that demonstrates natural objects including fashion apparel vividly have been emerged with the arrived era featuring e-commence such as personalized design systems [1,2] and recommendation systems [3]. In recent years, 3D modeling for textile has been intensively investigated. However, it was mostly concentrated on mechanical properties of textile [4] in terms of compressive response [5], shear damage [6], drape [7] based on Kinematic [8] and multiscale 3D geometric [9-11] modeling. Other realistic properties modeling such as heat transfer [12] on textile 3D modeling has also been seen investigated, but the optical spectral property has not been seen significant progress in 3D display environment. The reason may be that the colour rendering [1315] for 3D objects in computer industry has been standardized by BSDF (Bidirectional Spectral Distribution Function),however, it is complicated in that its number of modeling parameters attains to 16 for describing the spectral property of material [16] in 3D scene. Although it can be simplified to specific reflectance models corresponding to specific materials in practice such as "the defaultshading model for OpenGL and Direct3D until recent times" [17], the $3 \mathrm{D}$ graphic of garments is much false rendered in contrasting to realistic ones as we can see from related literatures. Therefore, the methods of appearance acquisition and representation of 3D garments should be investigated dedicatedly. The challenges of appearance acquisition and representation, to be specific, 3D colour measurements and rendering [18,19], exist in that the acquisition and modeling of the spectral of material [20].

If the reflectance of every point of garments are acquired and stored, it could be virtually displayed or represented electronically with varying illuminants. Multispectral imaging can be introduced for the efficient acquisition for the spectral contents of the colour appearance of the 3D natural object, such as the garments on human bodies in indoor or outdoor lighting environments. Multispectral imaging has been a branch of colour science since 1990s, which has many mature methods for the integration of 3D and multispectral data for cultural heritage applications [21]. Especially, it should be note that the potential of the concept of broadband multispectral imaging [22-24], by which we can acquire high dimensional spectra by using just a few spectral acquisition channels. A logical 3D spectral imaging system for garments colour acquisition should be the integration of multispectral camera and 3D scanning instruments. Several such integrations used for cultural heritage applications [21] can be borrowed as a consequence, to reconstruct 3D colour by the response of RGB camera would really be an innovate method for multispectral garments imaging. A solid example may be reconstructing the spectral of human skin successfully from the response of RGB digital camera under controlled imaging parameters [24].

Moreover, it is possible to capture spectral contents of garments by RGB response of camera cluster of mobile phones, which maybe the instant RGB pictures pasted to Facebook, Tweeter and so on from the internet. In principle, if the SPD (spectral distribution) of illuminants or daylight [25] and the sensitivity of camera [26] can be estimated from the time and the geographic location of images taken, the camera model can calculate the spectral reflectance. Although there has been no perfect algorithm yet to estimate the daylight of imaging scene and the spectral sensitivity, the positive tendency could be expected. From the review of the state of art 3D colour modeling for online appearance of fashion apparel above and my professional background, innovate improvements could be contributed to the colour community and garment engineering through subsequent endeavors. As an expectation, the intended targets of following research and academic plan could be briefed as following: 
i. To investigate colour measurement methods for 3D objects. With the developments of 3D graphics and virtue reality, it may be an international recognized pressing problem in the colour community. By far CIE has not been standardized it yet.

ii. To acquire the spectral contents of natural objects, especially of garments, under controlled or uncontrolled illuminants, even from internet connected environments by techniques from multispectral imaging and 3D shape modeling.

iii. To demonstrate 3D natural objects/garments in arbitrary illuminants or natural scene on electronic mediums by combining the techniques from 3D graphic and machine vision systems such as OpenGL and Open CV.

iv. To integrate data from other related aspects for the setup of useable and flexible functional modules satisfying for personalized design and retail recommendation in a humanin-loop e-commence ecology.

\section{References}

1. Fontana M, Rizzi C, Cugini U (2005) 3D virtual apparel design for industrial applications. Computer-Aided Design 37(6): 609-622.

2. Zhu X, Lu H, Rätsch M (2018) An interactive clothing design and personalized virtual display system. Multimed Tools Appl 77(20): 27163-27179.

3. Guan C, Qin S, Ling W, Ding G (2016) Apparel recommendation system evolution: An empirical review. International Journal of Clothing Science and Technology 28(6): 854-879.

4. Stig F, Hallström S (2012) Spatial modelling of 3D-woven textiles. Composite Structures 94(5): 1495-1502.

5. Ji W, Waas AM (2018) Modeling compressive response of 3D woven textile composites accounting for microscale geometric uncertainties. Advanced Composite Materials 28(2): 1-21.

6. Hufenbach W, Langkamp A, Hornig A, Zscheyge M, Bochynek R (2011) Analysing and modelling the 3D shear damage behaviour of hybrid yarn textile-reinforced thermoplastic composites. Composite Structures 94(1): 121-131.

7. Potluri P, Sharma S, Ramgulam R (2011) Comprehensive drape modelling for moulding 3D textile preforms. Composites Part A 32(10): $1415-1424$

8. El Said B, Green S, Hallett SR (2014) Kinematic modelling of 3D woven fabric deformation for structural scale features. Composites Part A 57: 95-107.

9. Weeger O, Sakhaei AH, Tan YY, Quek YH, Lee TL (2018) Nonlinear multi-scale modelling, simulation and validation of 3D knitted textiles. Applied Composite Materials 25(4): 797-810.
10. Eric Y, Bouteiller J, Song D, Baudry M, Berger T (2015) Volterra representation enables modeling of complex synaptic nonlinear dynamics in large-scale simulations. Frontiers in Computational Neuroscience 9: 112.

11. Tian M, Li J (2018) 3D heat transfer modeling and parametric study of a human body wearing thermal protective clothing exposed to flash fire. Fire and Materials 42(6): 657-667.

12. Rea M, Freyssinier-Nova J (2008) Color rendering: A tale of two metrics. Color Research and Application 33(3): 192-202.

13. Quintero J, Sudria A, Hunt C, Carreras J (2012) Color rendering map: A graphical metric for assessment of illumination. Optics Express 20(5): 4939-4956.

14. Vidmar Ž, Hladnik A, Tomc HG (2014) Performance assessment of three rendering engines in 3D computer graphics software. Acta Graphica 25(3-4): 101-114.

15. Pharr M, Humphreys G (2004) Physically based rendering: From theory to implementation. 1-27.

16. Guarnera D, Guarnera GC, Ghosh A, Denk C, Glencross M (2016) BRDF representation and acquisition. Computer Graphics Forum 35(2): 625650.

17. Hughes JF, Andries Van Dam, Morgan Mcguire, David F Sklar, Foley JD (2014) Computer graphics: Principles and practice (Third ed.) 1-184.

18. Guarnera D, Guarnera GC (2018) Virtual material acquisition and representation for computer graphics (1st ed.) 10(1): 1-101.

19. Simons G, Herholz S, Petitjean V, Rapp T, Ament M (2018) Applying visual analytics to physically based rendering. Computer Graphics Forum 38(1): 197-208.

20. Chane CS, Mansouri A, Marzani FS, Boochs F (2013) Integration of 3d and multispectral data for cultural heritage applications: survey and perspectives. Image and Vision Computing 31(1): 91-102.

21. Li S (2018) Filter selection for optimizing the spectral sensitivity of broadband multispectral cameras based on maximum linear independence. Sensors 18(5): 1455.

22. Li SX, Liao NF, Sun YN (2006) Optimal Sensitivity of Multispectral imaging system based on PCA. Opto Electron. Eng. 33: 127:132.

23. Wang X, Thomas JB, Hardeberg JY, Gouton P (2014) Multispectral imaging: Narrow or wide band filters? J. Int. Colour Assoc. 12: 44-51.

24. Xiao K, Zhu Y, Li C, Connah D, Yates JM (2016) Improved method for skin reflectance reconstruction from camera images. Optics Express, 24(13): 14934-14950.

25. López-Alvarez MA, Hernández-Andrés J, Romero J, Olmo FJ, Cazorla A (2008) Using a trichromatic CCD camera for spectral skylight estimation. Applied Optics 47(34): H31-H38.

26. Kawakami R, Zhao H, Tan RT, Ikeuchi K (2013) Camera spectral sensitivity and white balance estimation from sky images. International Journal of Computer Vision 105(3): 187-204. 
Your next submission with Juniper Publishers will reach you the below assets

- Quality Editorial service

- Swift Peer Review

- Reprints availability

- E-prints Service

- Manuscript Podcast for convenient understanding

- Global attainment for your research

- Manuscript accessibility in different formats ( Pdf, E-pub, Full Text, Audio)

- Unceasing customer service

Track the below URL for one-step submission https://juniperpublishers.com/online-submission.php 